\title{
LOS TRABAJADORES DE LOS TALLERES GRÁFICOS DE LA NACIÓN. DE LAS TRAMAS SINDICALES A LA CONCENTRACIÓN ESTATAL
} (1934-1940)

Sebastián Rivera Mir El Colegio Mexiquense

1 mural pintado en las paredes de los Talleres Gráficos de la
Nación (TGN) en 1936 utilizó como modelos a los propios trabajadores de la institución. Fueron sus mismos funcionarios quienes aparecieron retratados en distintas circunstancias laborales, sindicales y políticas. Así, los artistas buscaron plasmar de la manera más fehaciente las luchas que éstos habían emprendido y de paso convertirlos en actores de los procesos que enfrentaba el México cardenista. ${ }^{1}$

A diferencia de esta obra plástica, los rostros del Estado mexicano, de sus funcionarios, de sus burócratas, ha sido un tema escasamente abordado por los estudios historiográficos. En general se ha pensado la labor estatal desde una óptica estructural o funcionalista, sin detenerse en los sujetos que le dieron

Fecha de recepción: 21 de noviembre de 2017 Fecha de aceptación: 9 de marzo de 2018

\footnotetext{
${ }^{1}$ El mural fue pintado por Leopoldo Méndez, Pablo O'Higgins, Alfredo Zalce y Fernando Gamboa. Reproducciones de las distintas secciones pueden verse en el catálogo de la exposición "Pablo O'Higgins. Voz de lucha y de arte".
} 
cuerpo y sentido a cada una de sus decisiones de manera cotidiana y muchas veces rutinaria. Los actores sociales que constituyen el Estado no han sido un tema de importancia para los historiadores, a menos que nos refiramos a los presidentes, a los secretarios o a otros tipos de autoridades. ${ }^{2}$ Esta ausencia nos ha conducido a una evaluación del funcionamiento del Estado que oscila desde la omnipresencia de su capacidad represiva autoritaria hasta su caracterización como una institución fallida, corrupta o, en el “mejor" de los casos, ineficiente. Entre ambos extremos prácticamente no ha existido un espacio para comprender las prácticas estatales como el resultado de relaciones sociales, compuestas por negociaciones, presiones, limitaciones, posibilidades o arbitrariedades.

Avanzar en una reconceptualización de las dinámicas estatales durante el siglo xx requiere, a mi modo de ver, alejarnos de la idea del Estado como una entidad monolítica y realizar un análisis que despliegue el doble movimiento propuesto por Bohoslavsky y Soprano. Por un lado, despersonalizar al Estado, en el sentido de evitar comprenderlo como si fuera comparable a la identidad de una persona, capaz de decidir, impulsar, proyectar, por sí solo. Y por otro, personalizar al Estado, incorporando al análisis a los múltiples actores que construyeron sus prácticas cotidianas, percibiendo su carácter polifónico, inestable y en constante tensión. ${ }^{3}$ Esto significa retomar la polifonía tal y como lo propusiera Bajtín, no sólo a partir de la multiplicidad de voces, sino considerando que dicha coralidad se encuentra jerarquizada por medio de una lógica de poder que es necesario desentrañar. ${ }^{4}$ En el caso de esta investigación, como se verá a lo largo de sus páginas, esta diversidad de voces se expresa en las

${ }^{2}$ Cosío Villegas, El estilo personal de gobernar.

3 Bohoslavsky y Soprano, "Una evaluación y propuestas".

${ }^{4}$ López, "Nosotros también somos parte del pueblo"”, pp. 84-105. 
fuentes disponibles y de igual modo en los vacíos que también existen al respecto.

Para avanzar en esta agenda de largo plazo sin perdernos en el intento, el presente artículo analizará la experiencia de un particular grupo de trabajadores del Estado: los funcionarios de los Talleres Gráficos de la Nación. Éstos, durante el gobierno de Lázaro Cárdenas, establecieron su relación laboral a partir de la propuesta de crear una cooperativa propietaria de los talleres en los cuales se debía concentrar la labor editorial del Estado. El presupuesto federal no contemplaba una partida para esta entidad, que no recibía un peso a modo de asignación directa, pero aun así los trabajadores se esforzaron por desempeñar una función importante en los planes educativos, de propaganda y culturales de las diferentes instancias del gobierno cardenista. Estas especificidades, me parece, nos permiten un acercamiento no sólo a este grupo en sí, sino a las formas en que se articuló la relación entre el Estado posrevolucionario y sus propios trabajadores durante este periodo.

Los linotipistas, tipógrafos, cajistas, mecánicos, correctores y otras ocupaciones que se desempeñaron en los talleres, provenían de varias tradiciones organizativas que podemos rastrear hasta los albores del movimiento obrero local. ${ }^{5} \mathrm{~A}$ grandes rasgos, más allá de los matices que pudieran presentar, dadas las características ideológicas centrales de estos sectores de trabajadores, sedimentadas en buena medida desde un anarcosindicalismo o un socialismo a la mexicana, se mostraban reacios a vincularse con el Estado, a la participación política partidista y a la pérdida de autonomía sobre su ámbito laboral. Una investigación realizada por trabajadoras sociales en 1935 afirmaba que este sector representaba " $[\ldots]$ en el Distrito Federal, una categoría intermedia en el proletariado [...] tanto para obreros catalogados en una condición inferior, porque también éstos existen entre los

5 TAPia Ortega, Grito y silencio de las imprentas. 
obreros de las Artes Gráficas, como para obreros con un más alto nivel de vida". 6 Más allá de esta argumentación positivista, sobre estos trabajadores pesaba la idea de representar a los obreros en general, debido tanto a su capacidad organizativa como a sus condiciones materiales. Y aunque esto no pasara de ser un prejuicio ampliamente extendido, ${ }^{7}$ fue adoptado por ellos mismos, por lo que resulta interesante cómo este sector se relacionó con las propuestas realizadas desde el cardenismo para construir una base de trabajadores al servicio del Estado, del partido y de la familia revolucionaria. ${ }^{8}$

Para analizar esta disyuntiva, nos enfocaremos en tres procesos paralelos que enfrentaron y que constituyeron el trasfondo de las negociaciones y tensiones del periodo en estudio. En primer lugar, nos concentraremos en los esfuerzos sindicales por mantener su tuición sobre el espacio laboral y convertirse en el interlocutor autorizado entre obreros, empleados, jefes, propietarios y funcionarios estatales. Un segundo eje analítico se relaciona con la dinámica impuesta por el impulso cooperativista del gobierno de Cárdenas, que rearticuló los equilibrios políticos y las prácticas laborales dentro de los talleres. Y, por último, nos detendremos en los problemas entre trabajadores de distintas dependencias estatales que generó el fortalecimiento de los Talleres. La exclusividad de la labor editorial que se otorgó a esta entidad supuso el fin de las pequeñas y medianas imprentas que habían mantenido algunos departamentos, lo que incluyó la reinserción de sus operarios en la planta de los TGN. En términos generales, este proceso de concentración implicó una reestructuración intraestatal, mientras que los cambios impulsados por el nuevo cooperativismo significaron debates a

6 SAlgado, El costo de la vida de los obreros de artes gráficas, p. 1.

7 Para el caso argentino, por mencionar uno al otro extremo del continente, véase CERuso, “Los trabajadores gráficos entre 1916 y 1943”, pp. 43-61.

8 Anguiano, El Estado y la politica; León y Marván, La clase obrera; AsHBy, Organized Labor. 
nivel interno en los propios Talleres y, finalmente, las disputas sindicales expusieron tensiones extraestatales. De ese modo, se propone como premisa que para analizar los procesos que afectaron a los trabajadores de los Talleres Gráficos de la Nación, y no sólo a ellos, es necesario no perder de vista estos tres niveles diferenciados y considerar especialmente cómo se articularon en las distintas etapas del cardenismo.

\section{UNIONES, SINDICATOS, FEDERACIONES}

Hasta la asunción del cardenismo en 1934, la estructura laboral de los Talleres Gráficos de la Nación respondía a las divisiones gremiales que se habían desarrollado en el ámbito editorial desde el siglo xIx. A juicio de los trabajadores, el origen de esta entidad se relacionaba con el establecimiento de la imprenta de la Secretaría de Fomento en 1883, ${ }^{9}$ y desde ese entonces distintas agrupaciones mantenían funcionarios o mejor dicho plazas laborales en su interior, las cuales podían controlar con una relativa autonomía. Así, los tipógrafos dependían de su asociación gremial, mientras que los linotipistas podían estar separados entre los del Sindicato Nacional de Linotipistas, la Unión Linotipográfica de la República Mexicana (ULRM) o alguna otra institución menor. Algo similar se repetía en las distintas labores. Esta estructuración, que controlaba el ingreso, el sistema

\footnotetext{
9 Si bien el relato "mitologizado" de sus propios trabajadores señala que los Talleres Gráficos de la Nación se crearon en el siglo xIx, sólo a mediados de la década de 1920 se dictó el acuerdo presidencial para fusionar las imprentas de la Secretaría de Fomento, del Diario Oficial, de la Secretaría de Relaciones Exteriores y de la Secretaría de Educación Pública. Las maquinarias sólo pudieron concentrarse a principios de 1930 y consistían en 12 linotipos, más de 20 prensas mecánicas, una dúplex rotativa para elaborar periódicos, máquinas de doblar, prensas hidráulicas, máquinas de coser, cortadoras, de litografía, de fotograbado, entre varias otras (además se incluían los talleres auxiliares de fundición, herrería, carpintería, estereotipia, electricidad y mecánica). Véase Talleres Gráficos de la Nación, Homenaje de los obreros y empleados.
} 
de aprendices y maestros, los salarios, las horas de trabajo, los ascensos, las cuotas sindicales, entre otros elementos, se reflejaba en la construcción de federaciones, alianzas o uniones, que permitían negociar colectivamente los derechos y deberes de los trabajadores. El problema de este tipo de estructura se hizo más complejo cuando a mediados de la década de 1920 las imprentas y talleres de varias secretarías se fusionaron y sus trabajadores fueron concentrados en una sola dependencia, que además poseía la exclusividad como el impresor y editor del Estado mexicano. En aquel momento, los conflictos fueron acallados por la abrumadora presencia de la Confederación Regional Obrera de México (СROM) entre los trabajadores de este nuevo espacio. Su fortaleza impulsó la creación de la Unión de Obreros de Artes Gráficas de los Talleres Oficiales, que se incorporó a la Federación Nacional de Artes Gráficas. ${ }^{10}$ La Unión planteaba en sus estatutos su autodefinición como "agrupación de resistencia”, impulsaba la escuela racionalista entre sus miembros y destacaba su autonomía en la negociación con el gobierno. ${ }^{11}$ Pero pese a esta autonomía discursiva, sus relaciones con el Estado y con el organismo suprasindical eran tan estrechas que, por ejemplo, en 1925 el secretario general de la CROM, Eduardo Moneda, se desempeñaba como director de los TGN.

Para comprender el carácter que poseían las relaciones laborales de la mayoría de los talleres de artes gráficas, podemos recurrir a la definición que realizaron los miembros de la Unión Linotipográfica de la República Mexicana. A su juicio, el contrato colectivo

10 En 1924, la Unión de Obreros de Artes Gráficas de los Talleres Oficiales se transformó en la Unión de Obreros y Empleados de Artes Gráficas de los Talleres Oficiales, un pequeño cambio de nombre, pero que implicaba dar un giro a las políticas obreristas de los trabajadores de los Talleres. REZA, "Pasado, presente y futuro", pp. 39-45.

${ }^{11}$ Estatutos de la Unión de Obreros de Artes Gráficas de los Talleres Oficiales. 
[...] es la serie de bases normativas y generales que se reglamentarán por medio de los contratos GREMIALES; dicho de otra manera: el contrato colectivo es acto previo de inteligencia entre las partes para proceder después al otro acto principalísimo: la aplicación de esa inteligencia por cada sindicato o unión cuyas peculiaridades demandaron la existencia del contrato gremial para fijar concretamente las relaciones obrero-patronales. ${ }^{12}$

Con este esquema se pretendía defender la particularidad del linotipista, que a diferencia de todos los demás trabajadores “[...] no tiene oportunidad de obtener más sobresueldo que aquel que emerge de servir muy eventualmente horas extraordinarias y dentro de un mismo día". ${ }^{13}$ A esto se sumaba una larga lista de especificidades. De ese modo, se conjugaban los intereses generales de los trabajadores de determinado taller con las necesidades gremiales. Mientras todos los gremios que participaban en las negociaciones estuvieron dispuestos a agruparse en federaciones o alianzas y negociar acuerdos beneficiosos para todas las partes, no hubo grandes problemas.

Sin embargo, desde comienzos de la década de 1930, la relación entre la CROM, el gobierno y los trabajadores se debilitó, y las estructuras federativas fueron abandonadas; ${ }^{14}$ los trabajadores debieron guarecerse en sus aparatos gremiales de origen $\mathrm{y}$, aún peor, la crisis financiera global precarizó las condiciones laborales y agudizó las dificultades económicas de los propios Talleres. El 31 de diciembre de 1930 se despidió a la mayoría de

12 "Informe del comité ejecutivo de la ULRM a la asamblea sobre los resultados de la huelga en los talleres de Excélsior", 1o de julio de 1931, en FHVLT, Id. 10407, leg. 103, f. 4.

13 "Informe del comité ejecutivo de la ULRM a la asamblea sobre los resultados de la huelga en los talleres de Excélsior”, 1 de julio de 1931, en FHVLT, Id. 10407, leg. 103, f. 5.

${ }^{14}$ Una revisión de este proceso, iniciado en 1928, en Leal, Agrupaciones y burocracias sindicales en México, pp. 190 y ss. 
sus trabajadores y “[...] pudo darse por terminada esa situación ya insostenible respecto a sindicatos y desde entonces el personal que aquí labora quedó incorporado a los empleados federales”, establecía un optimista informe realizado a mediados de 1931 por Salvador Vázquez Gómez, interventor de la Contraloría. De hecho a continuación exponía que: "Todos aquellos ex obreros que se caracterizaron por su actitud disolvente, que provocaron escándalos y que continúan tratando de provocarlos, han sido rechazados por los que hoy laboran perfectamente convencidos de que son más felices sin estar afiliados a ningún sindicato o unión". ${ }^{15}$ Pero pese a estas palabras que autoelogiaban su intervención, las querellas internas, las desconfianzas, las acusaciones se convirtieron en prácticas cotidianas durante casi toda la primera mitad de la década de 1930 y las disputas intergremiales no desaparecieron como auguraba el funcionario de la Contraloría. ${ }^{16}$

Una semana después de que Lázaro Cárdenas asumió la presidencia en diciembre de 1934, los trabajadores de los Talleres se reunieron en asamblea para discutir algunos de estos temas. El director, Roberto Quirós Martínez, inició la sesión presuponiendo la rudeza de los enfrentamientos: “[...] suplico - expuso - tengan la bondad algunos de los señores que hagan uso de la palabra, que puntualicen cuáles son por parte de la Dirección, los errores, las injusticias o algún acto que merezca verdadera censura". ${ }^{17}$ En un escenario crispado desde el inicio,

15 Ambas citas en: "Informe del delegado contable de la Contraloría Salvador Vázquez Gómez”, 7 de julio de 1931, en AGN, SHCP, sección Secretaría Particular, c. 20, exp. 101/093.6/56, p. 2.

16 Véase "Talleres Gráficos de la Nación”, 1934, en AGN, $A R$, c. 16, exp. 139/164-4.

17 "Acta y versión taquigráfica de la asamblea general de los Trabajadores de los Talleres Gráficos de la Nación”, 7 de diciembre de 1934, en AGN, LC, c. 372, exp. 432/8, f. 55. El director llevaba a cabo una campaña de depuración del personal atendiendo a su antigüedad y eficiencia, debido a que reconocía que había un exceso de obreros supernumerarios (maestros especializados) en 
el tipógrafo michoacano y partidario de Cárdenas, Rafael R. Gascón, tomó la palabra. Pese a llevar menos de dos años en la institución había sido uno de los principales impulsores de la creación del Sindicato de los Talleres Gráficos de la Nación, algo que molestaba a quienes se adscribían a las estructuras gremiales tradicionales, pero que se encontraba en las bases de la propuesta cardenista para los trabajadores. ${ }^{18}$ Gascón trataba de poner el tema en debate, sin generar más conflicto: "Se nos ataca de habernos avorazado a formar un Sindicato sin haberlo comunicado a todos, yo quiero que dentro de un ambiente sereno, se discuta la formación de este Sindicato advirtiendo a toda la Asamblea, para poder seguir hablando, que todos los oradores a quienes digan algo altisonante o fuera de tono, se les expulse de la Asamblea" ${ }^{19}$ Como suele suceder después de este tipo de advertencias, el discurso del orador estuvo repleto de acusaciones de distintos calibres, que incluso en la versión taquigráfica se trasluce la rispidez y el encono de los enfrentamientos. Pero concentrándonos en los problemas que nos interesan, podemos rescatar que la intención del Sindicato recién formado era, por un lado, negociar con las autoridades del gobierno el envío de trabajos, tal y como lo disponían las medidas que le otorgaban exclusividad a los Talleres. Y por otro, el orador destacaba: "No queremos absorber un puesto que no podamos desempeñar, esta naciente institución será completamente diferente a todas aquellas que han existido antes, llenas de anomalías, que únicamente mangoneaban y vivían a costillas de todo el elemento

relación con el volumen de trabajo con que contaban los Talleres. "Carta de Roberto Quirós, director de los TGN a Vicente Lombardo Toledano", 24 de mayo de 1934, en FHVLT, Id. 14069, leg. 240.

18 CóRdova, La politica de masas del cardenismo, pp. 123 y ss.

19 "Acta y versión taquigráfica de la asamblea general de los Trabajadores de los Talleres Gráficos de la Nación”, 7 de diciembre de 1934, en AGN, $L C$, c. 372 , exp. $432 / 8$, fs. 56-57. 
trabajador" ${ }^{20}$ Con esto se hacía referencia no sólo al mecanismo de asignación de plazas y la cláusula de exclusividad que aplicaban los gremios y que impedía a los no agremiados trabajar en los talleres que controlaban, sino al pago que muchas veces los funcionarios debían realizar a la entidad gremial que los había puesto en determinado lugar.

Después de Gascón, fue el turno de José Refugio Rodríguez, impresor y militante vinculado a los orígenes de Partido Comunista Mexicano. Sus palabras, en apoyo al anterior orador, contextualizaron la creación del nuevo sindicato, vinculándolo con el fin de las centrales "corrompidas", con las políticas obreristas de Cárdenas, con la formación de sindicatos en otras dependencias estatales, con objeto de "[...] depurar la política obrera que desgraciadamente ha ensombrecido el porvenir de los obreros mexicanos". ${ }^{21}$ Lo relevante del nuevo espacio organizacional sería que no permitiría la intromisión de "elementos" de otros gremios que desorientaran a los trabajadores, y además, serviría para consolidar la idea de Cárdenas de que el Estado "sí es patrón", por lo que las leyes del trabajo deben aplicarse a sus funcionarios. Esto se relacionaba además con los cambios introducidos por el nuevo Código del Trabajo de 1931 y con la inestabilidad que provocaba entre los trabajadores el hecho de que no estuvieran asignados sus sueldos en ninguna partida presupuestal. ${ }^{22}$

20 “Acta y versión taquigráfica de la asamblea general de los Trabajadores de los Talleres Gráficos de la Nación”, 7 de diciembre de 1934, en AGN, LC, c. 372, exp.432/8, f. 58.

21 "Acta y versión taquigráfica de la asamblea general de los Trabajadores de los Talleres Gráficos de la Nación”, 7 de diciembre de 1934, en AGN, LC, c. 372 , exp.432/8, fs. 60-61.

22 Estos debates también deben insertarse en la búsqueda de un estatuto jurídico para los trabajadores del Estado, emprendida por Cárdenas desde el comienzo de su mandato, la cual había generado discrepancias sobre las atribuciones que les quería otorgar, entre otras, el derecho a huelga. Sobre estos debates Córdova, La política de masas del cardenismo y AsHby, Organized Labor. 
Las voces disidentes comenzaron con Luis Solís, jefe de departamento y también proveniente del movimiento obrero michoacano..$^{23}$ En su alocución recriminó duramente a los organizadores del sindicato por haber comenzado su agrupación por arriba, con un pequeño grupo, sin hacer un llamamiento general a todos los trabajadores. Edmundo González, por su parte, recordó la creación de la Unión de Obreros de Artes Gráficas de los Talleres Oficiales en 1920, para destacar que era una organización que defendía a los trabajadores sin importar el gobierno en turno. La situación del sindicato parecía evidenciar lo contrario y seguir sin reflexión lo que proponía el cardenismo. "Quiero estar codo a codo con aquellos elementos que digan vamos a luchar por determinada idea, allí estaría yo, compañeros, pero la verdad voy a pertenecer a esa agrupación si pertenece la mayoría, porque soy ante todo disciplinado, pero sí iré con el rubor muy honrado de ir a calentarme al sol que nace”, explicaba González dando cuenta de su experiencia como orador. Aunque al parecer en este ámbito el prócer era Higinio C. García, quien además de tipógrafo y antiguo miembro de los Batallones Rojos, había incursionado en la poesía y la dramaturgia. ${ }^{24}$ En sus palabras destacaba que la idea de formar un nuevo sindicato no era nueva, el problema era que la organización creada no tenía contenido, es decir, se había fundado sin saber para qué servía y lo peor, "sin estatutos". Además, no se había reconocido la experiencia, a veces dolorosa, que tenían los trabajadores, por lo que se ponía en duda "[...] la fraternidad que

${ }^{23}$ Esta procedencia era relevante por la vinculación con Cárdenas y especialmente porque el nuevo sindicato contaba con el apoyo legal de la Confederación Revolucionaria Michoacana del Trabajo. De igual modo, una práctica común en el mundo editorial privado era que los dueños recurrieran a trabajadores foráneos en caso de huelgas o problemas. Esto parece haberse implementado en el caso de los TGN, aunque no hay datos suficientes para confirmarlo.

${ }^{24}$ Véase por ejemplo García, Justicia divina. Drama social en cuatro actos. 
debe imperar entre todos los miembros de una misma familia". ${ }^{25}$ Éste era uno de los núcleos de la discusión: cómo se contemplaban los trabajadores a sí mismos. Y los formadores del nuevo sindicato habían excluido a los "jefes de departamento", con lo que rompían las dinámicas organizativas tradicionales, que comprendían a todos los miembros del taller como una gran familia, donde los "maestros" debían tutelar la formación de los aprendices, donde las jerarquías no se ponían en discusión.

Como podemos ver, los oradores (en total fueron tres a favor y tres en contra, como establecía el reglamento interior de discusiones $)^{26}$ correspondían a obreros experimentados, no sólo como expositores, sino en los amplios ámbitos que involucraba la organización de los trabajadores. Y aunque esto no puede simplemente extrapolarse a los cerca de 300 funcionarios de los Talleres, es relevante destacar que, dadas las formas de organización laboral y sus encrucijadas gremiales, la politización y participación envolvía a buena parte de ellos. De hecho, el contexto de crispación e involucramiento se trasladaba incluso a los libros que imprimían los propios talleres. En un texto en homenaje a Obregón, Calles, Abelardo L. Rodríguez y Cárdenas, destinado a explicar su importancia a este último, escribieron no sólo dos o tres jefes de departamento, sino una amplia gama de trabajadores que no perdió el tiempo con palabras cordiales de saludo, al contrario, hizo propuestas concretas para reorganizar su espacio laboral. ${ }^{27}$

$\mathrm{Al}$ respecto, el director Quirós Martínez, prácticamente iniciando su introducción, señalaba:

\footnotetext{
25 "Acta y versión taquigráfica de la asamblea general de los Trabajadores de los Talleres Gráficos de la Nación”, 7 de diciembre de 1934, en AGN, LC, c. 372, exp. 432/8, f. 69.

26 "Reglamento interior de discusiones", anexo a los Estatutos de la Unión de Obreros de Artes Gráficas de los Talleres Oficiales.

27 Talleres Gráficos de la Nación, Homenaje de los obreros y empleados.
} 
Estos trabajadores, dignificados en el taller, han sido engañados más de una vez; así, pues, hay razón para que algunos hombres no gocen ya del respeto, de la consideración ni del prestigio que en los pasados días entretejieron coronas de laureles y de rosas en sus sienes. El ambiente que respiran no tiene el calor de la simpatía comprensiva, sino la hosquedad encubridora de un agrio desdén..$^{28}$

El también escritor y periodista insistía en deslindarse de los deshonestos, de quienes saboteaban al gobierno y de otros tantos malos elementos que desde fuera de los talleres entorpecían su funcionamiento en servicio de la revolución. Aunque en ese mismo volumen otros articulistas se preocuparon menos por las formas y pusieron con nombres y apellidos a aquellos directores y subdirectores que desde 1930 habían desmantelado no sólo los talleres, sino incluso hasta el fondo de defunción que tenían los trabajadores. ${ }^{29}$

En este contexto la nueva administración cardenista, y en especial el nuevo esquema sindical propuesto, sirvió, junto con debilitar el control cromista de los Talleres, para que el propio presidente colocara a sus partidarios en este espacio laboral. Con esto se rompió la estructura de incorporación tradicional que establecía que cada año se debían admitir “[...] aprendices hasta un número equivalente al diez por ciento de los obreros, dándose preferencia a los hijos de éstos”. ${ }^{30} \mathrm{El}$ primer director de los TGN nombrado por Cárdenas fue Abraham Mejía, quien también provenía de Michoacán. Un par de semanas después de su nombramiento, recibió un listado de hombres y mujeres para que "de ser posible" se les permitiera trabajar en los Talleres. "Las personas incluidas en la lista - escribía el secretario particular de la presidencia, Luis I. Rodríguez - forman parte de

28 Quirós Martínez, “El ideal de los trabajadores”.

29 Véase RezA, "Pasado, presente y futuro”, pp. 39-45.

30 “Acuerdo relativo al funcionamiento de los Talleres Gráficos de la Nación”, Diario Oficial (8 ene. 1934), p. 98. 
la Confederación Revolucionaria Mexicana del Trabajo y de ahí el interés del señor presidente". ${ }^{31}$ El mensaje concluía señalando que se agradecería que se contratara a los candidatos en los puestos recomendados. El problema para el director de los Talleres no era encontrar espacio para los conserjes, la enfermera o el electricista, sino para un par de agentes ejidales, otro par de inspectores escolares y un agente sanitario. La lista de personas propuestas ni siquiera calzaba con las necesidades de los TGN. ${ }^{32}$

En ese mismo periodo, peticiones similares fueron realizadas por Vicente Lombardo Toledano, máximo dirigente de la Confederación General de Obreros y Campesinos de México (CGOCM) y posteriormente de la Confederación de Trabajadores de México (Стм). Lombardo era un líder reconocido por la mayoría de las agrupaciones vinculadas al mundo del impreso. ${ }^{33}$ Había apoyado a muchas en la elaboración de sus estatutos, en sus conflictos legales, e incluso antes de la ruptura con la CROM, se había desempeñado como representante de la Alianza de Uniones y Sindicatos de Artes Gráficas. En el nuevo escenario abierto por el cardenismo se había afianzado como el principal organizador del movimiento obrero y especialmente después de su gira por la Unión Soviética, en 1935, se convirtió en un

31 "Memorándum de Luis I. Rodríguez a Abraham Mejía”, 11 de enero de 1935, en AGN, $L C$, c. 1322, exp. 710.1/123, f. 2.

32 En otras ocasiones el secretario de Cárdenas enfatizó las habilidades para el cargo de sus recomendados. Por ejemplo, en el caso de Manuel Elizalde, "grabador en fotograbado", Rodríguez expresó que tenía “[...] la impresión de que el señor Elizalde conoce la técnica de su oficio y es por ello que te ruego le impartas tu valiosa ayuda”. Gustavo Ortiz Hernán, director de los Talleres en esta ocasión, respondió afirmativamente, aunque el expediente muestra que Elizalde no obtuvo trabajo en los Talleres. "Recomendación a favor de Manuel Elizalde”, septiembre de 1936, en AGN, LC, c. 1341, exp. 710.1/1796, cita en f. 7.

${ }^{33}$ En el Fondo Histórico Vicente Lombardo Toledano de la Universidad Obrera se resguardan documentos y cartas con este tipo de solicitudes desde 1923 hasta avanzada la década de 1940. 
líder a nivel continental. ${ }^{34}$ De igual modo, este acercamiento con la URSS sirvió para apaciguar sus relaciones con el Partido Comunista de México (PCM). En relación con los trabajadores de los Talleres Gráficos de la Nación, Lombardo Toledano se convirtió en uno de sus consejeros y a la vez en un vínculo con el Poder Ejecutivo y otras autoridades estatales. En su archivo se evidencia cómo se desarrollaron los lazos, primero con la CGOCM y después con la CTM, a la cual adhirió con entusiasmo el Sindicato de los TGN.

En este proceso de reconfiguración de alianzas políticas, estos trabajadores mostraron un particular activismo. En lugar de esperar invitaciones o adherir de manera pasiva, buscaron influir en el destino de las agrupaciones e iniciativas en las que se embarcaban. Un caso interesante es el proceso de creación de la Editorial México Nuevo. La asamblea sindical evaluó que “[...] en México padecen los escritores revolucionarios, faltos en la actualidad de todo estímulo y cuyas obras, o se ignoran lamentablemente por permanecer inéditas largos años, o bien, cuando se imprimen, quedan sujetas a toda suerte de apetitos mercantiles" ${ }^{35}$ Por lo que hicieron gestiones con la LEAR y con el periódico El Nacional para impulsar una editorial; éstos colaborarían con escritores, artistas y grabadores, y los funcionarios se comprometieron a realizar el trabajo voluntaria y gratuitamente. El logo de la nueva empresa, especializada en la difusión del marxismo, fue un puño sobre una máquina de escribir y un linotipo, conjugando la labor manual con el trabajo intelectual, tal y como se impulsaba en las distintas agrupaciones que buscaban la formación de un frente único. La presencia de los trabajadores en esta iniciativa era tan relevante que, a diferencia de muchas

${ }^{34}$ Herrera González, "Vicente Lombardo Toledano y el Congreso Obrero Latinoamericano (1935-1938)”, pp. 109-150. También ILLADEs, Las otras ideas.

35 Editorial México Nuevo, “Explicación”, p. 202. 
otras editoriales, se incluyeron los nombres de los implicados en los libros. En uno de estos casos encontramos:

Ejecutó el original en teclado de monotipos la obrera María Hernández Zarco; fundió la composición Rafael Herrera; formó e impuso Celso V. Morales; imprimieron los prensistas Simón Esteves, Ruperto Castilla, José Hernández Lara, J. de la Cruz Murillo, Alfredo Escobar, José Nevares, Tomás Osorio, José González, Alberto Vélez y Enrique H. Arce, a las órdenes del maestro Ignacio Hernández. La labor de encuadernación fue dirigida por el maestro Ignacio Gutiérrez. La viñeta y el exlibris que lo exornan, aparte de la litografía de Zalce, son obra de Salvador Pruneda. ${ }^{36}$

Esta práctica, poco recurrente en el mundo editorial, destaca la importancia que daban los trabajadores a los procesos que decidían emprender.

Para el desarrollo de este tipo de vínculos fue crucial el nombramiento de Gustavo Ortiz Hernán como director de los TGN, a fines de 1935. Antes de esta designación, ya era considerado un actor importante en los circuitos culturales mexicanos; escribía en El Nacional y en la revista Futuro, además había ganado el Premio Nacional de Periodismo. También era miembro de la LEAR, y muy cercano al Taller de Gráfica Popular y la Universidad Obrera. De hecho, uno de los delegados de la célula comunista de los TGN, al VI Congreso del PCM en enero de 1937, explicaba que el crecimiento de esta organización en su interior

${ }^{36}$ Rodríguez, Veinte discursos, p. 207. Véase también Ortiz Hernán, Chimeneas. En este caso, además de la larga lista de trabajadores implicados, aparecen detalles como las características del papel, los nombres de los tipos utilizados y el tiraje. Algunos ejemplares incluso se encuadernaron en piel. En su introducción el autor escribe: "Atraen alabanza sin reservas, la esforzada abnegación y el cariño que mis camaradas tipógrafos destinaron a la ejecución material de este trabajo, tan difícil por la utilización simultánea de diversos recursos: ornamentaciones, combinación de tipos, fotografías, blancos y signos", p. 10. 
se debía a la llegada de Ortiz Hernán y Margarita Gutiérrez. Antes de que ambos se incorporaran a la dirección de la entidad se perseguía cualquier intento comunista por penetrar entre los funcionarios. Ya desde 1935 la situación se había revertido, y cuando el delegado hizo su exposición eran 38 los integrantes de la célula comunista. De hecho, para demostrar sus capacidades se comprometía a "[...] imprimir cinco mil ejemplares del discurso del Camarada Laborde, como el saludo que traemos; es decir, no son palabras, son hechos con los que nosotros tratamos de responder en este instante". ${ }^{37}$ Unos meses después, el Sindicato de Trabajadores de los Talleres Gráficos de la Nación se embarcó en la candidatura de Hernán Laborde, secretario general del PCM, a diputado por el Distrito Federal. ${ }^{38}$

Como vimos, uno de los resultados de estos vínculos fue el mural que mencionamos al comienzo de este artículo. Y aunque pudiera parecer una más de las muestras artísticas del periodo, simbolizó un punto de inflexión en las acres disputas entre los trabajadores de Talleres y los integrantes de la CROM. Junto con los rostros de los funcionarios (Enrique Ramírez y Ramírez y Carmen Molina, entre otros) y los nombres de los albañiles participantes, Pablo O’Higgins decidió también incluir a Luis N. Morones, una propuesta que fue cuestionada por las autoridades de la Secretaría de Gobernación, que preferían aquietar las aguas y evitar algún tipo de sabotaje justo en el momento en que se había creado una nueva central obrera, la Confederación de Trabajadores de México. En el mural, Morones representaba al enemigo de los obreros organizados, la corrupción y

\footnotetext{
37 “Actas del VI Congreso del Partido Comunista de México", enero de 1937, en Archivo CEMOS, fondo PCM, c. 11, exp. 1, p. 360.

${ }^{38}$ En dicho momento la dirección del Sindicato estaba formada por Guillermo Mayoral, secretario general; José de la Luz Murillo, secretario de Interior; Salvador Reyes, secretario del Trabajo; Ramón Grimaldo, secretario de Acuerdos; y Guillermo Segura, secretario de Archivo y Bibliotecas. "Elecciones para diputados federales", 1937, en AGN, IPS, c. 183, exp. 3.
} 
la violencia, por lo que la CROM presentó una queja ante dicha dependencia, que a su vez presionó al artista para que modificara el rostro del líder sindical. A la respuesta positiva de la Secretaría, siguió un debate canalizado a través de las páginas de Frente a Frente, órgano oficial de la $\operatorname{LEAR}^{39}$ y peticiones por parte del Sindicato para que el presidente rectificara la decisión. ${ }^{40} \mathrm{El}$ silencio de Cárdenas a estas solicitudes al parecer hizo que los artistas encargados del mural optaran por no continuar presionando y cambiaran las facciones del rostro de Morones. Las disputas intergremiales se habían apaciguado a partir de las propuestas cardenistas.

\section{EN BUSCA DE LA CONCENTRACIÓN DE LOS IMPRESOS}

Desde comienzos de la década de 1920, el objetivo que trazaron los distintos presidentes a los TGN había sido concentrar los trabajos editoriales. Sin embargo, esto no fue bien recibido por las distintas dependencias gubernamentales, poco dispuestas a perder su autonomía en esta materia. Los intentos fueron diversos y las directrices presidenciales recursivamente fallaron en este propósito. Por ejemplo, en una de estas acciones surgieron problemas entre el director de los Talleres y el secretario de Educación, debido a la doble orden presidencial que por un lado pedía que $20 \%$ de la producción editorial del Estado fuera entregada a la Secretaría de Educación Pública (SEP) para que cumpliera con sus fines educativos, y por otro se encomendaba a los Talleres cumplir con la distribución de este porcentaje. El resultado fue que el director de los Talleres gravó en una cantidad similar toda la producción de la SEP, para reunir los recursos para hacer dicha

${ }^{39}$ Este periódico era subsidiado por los Talleres. Véase LEAR, Picturing the Proletariat.

40 "Protesta por mutilación de murales-Talleres Gráficos de la Nación", noviembre de 1936, en AGN, $L C$, c. 1107, exp. 609/341. Véase también LóPEZ Orozco, "Los murales de O'Higgins", pp. 91-111. 
distribución. ${ }^{41}$ Eso encarecía los libros proyectados por dicha Secretaría, por lo que la decisión fue resistida por sus directivos. Así, éste y otros problemas similares impidieron que se avanzara en la consolidación de los Talleres como centro editorial exclusivo del Estado mexicano.

La respuesta de Lázaro Cárdenas a este tipo de conflictos fue un poco más hábil que las presentadas por sus antecesores. En primer lugar, traspasó la administración de los Talleres de la Secretaría de Economía Nacional a la de Gobernación, lo que significaba mandar un mensaje relevante respecto a la función que esperaba que desempeñaría la entidad durante su mandato. ${ }^{42}$ En segundo plano, en vez de dictar una orden coercitiva sobre la obligatoriedad de imprimir en los Talleres, optó por insistir en que la Tesorería de la Federación anticiparía a las dependencias gubernamentales $80 \%$ del valor de los trabajos que solicitaran a los TGN. ${ }^{43}$ Con este nuevo esquema se reforzaba la directriz de que los productos editoriales del Estado debían hacerse en una sola institución. ${ }^{44}$

41 “Talleres Gráficos de la Nación. Transcribe acuerdo presidencial”, 1930, en AGN, IPS, c. 32, exp. 29.

${ }^{42}$ En septiembre de 1933, los Talleres habían pasado a depender de la Secretaría de Economía Nacional, aunque su consejo técnico integraba representantes de la mayoría de las secretarías y algunos departamentos. Esto duró algunos meses y cuando Lázaro Cárdenas asumió el poder pasaron a la Secretaría de Gobernación. Véase "Acuerdo relativo al funcionamiento de los Talleres Gráficos de la Nación”, Diario Oficial (8 ene. 1934), pp. 97 y 98; y “Acuerdo por el cual se dispone que los Talleres Gráficos de la Nación pasarán a depender de la Secretaría de Gobernación”, Diario Oficial (27 dic. 1934), p. 1037.

${ }_{43}$ Esto fue impulsado durante la presidencia de Abelardo Rodríguez, pero al parecer había sido escasamente utilizado por las reparticiones públicas. Véase "Acuerdo que aclara el de 7 de septiembre de 1934, en lo relativo al anticipo por pedidos que se hagan a los Talleres Gráficos de la Nación”, Diario Oficial (28 dic. 1934), p. 1078.

${ }_{44}$ El 11 de enero de 1935 un nuevo acuerdo presidencial insistió en esta exclusividad, aunque incorporó como excepción a la Oficina Impresora de Estampillas de la Secretaría de Hacienda y a la Secretaría de Relaciones Exteriores, que 
Para comprender la importancia que Cárdenas mismo otorgó a los impresos podemos revisar brevemente el caso de un folleto de propaganda sobre la repartición de tierras en Yucatán. El proceso comenzó directamente con una carta del presidente al escritor yucateco Luciano Kubli en la que le solicitaba que redactara unas páginas sobre el tema. La petición enfatizaba la necesidad de la divulgación escrita como mecanismo para dar continuidad a la gira que había realizado recientemente por la península. Este encadenamiento gira/propaganda ha sido poco explorado por la historiografía cardenista, pero fue un recurso utilizado en varias ocasiones por el Ejecutivo. ${ }^{45}$ Para Cárdenas esto permitía que su presencia y sus postulados se mantuvieran en los lugares ya visitados. "Con la finalidad anterior debe usted -le pidió a Kubli- escribir un folleto corto, hablando de la bondad del ejido; folleto corto de cinco o seis hojas para imprimirse en letra grande, con conceptos comprensivos para la clase campesina y con un párrafo dedicado a la clase media [...] extendiéndose usted en otro párrafo hasta la escuela socialista”. 46 Al final de la carta, escrita a mano, Cárdenas hizo una propuesta de título: El ejido en Yucatán. Después de estas instrucciones, el proceso editorial comenzaba. Los Talleres entregaban su cotización, firmada por el jefe del Departamento Técnico, en un solo párrafo detallando el papel malinche a utilizar, la cantidad de ejemplares, la carátula en tricromía, los forros en couché y otros detalles similares. Entre la petición al escritor y el inicio de la

poseía su propio taller. Véase "Acuerdo por el cual se previene que las Secretarías y Departamentos de Estado, deberán encomendar sus trabajos de imprenta a los Talleres Gráficos de la Nación”, Diario Oficial (11 ene. 1935), pp. 1 y 2. ${ }^{45}$ Kubli mismo escribió el relato de esta gira; véase Kubli, Sureste proletario. Apuntes de una jira fecunda. Las ilustraciones de este libro las hizo Salvador Pruneda. Quien desarrolló este tipo de difusión con maestría fue Roberto Hinojosa, un propagandista boliviano emigrado a México. Véase, entre otros, Hinojosa, El tren olivo en marcha.

46 "Carta de Lázaro Cárdenas a Luciano Kubli”, 27 de febrero de 1935, en AGN, LC, c. 1301, exp. 704.1/73, sin foliar. 
distribución de 10000 ejemplares en Yucatán, sólo pasaron 45 días. Los trabajadores de los TGN habían puesto su esfuerzo en cumplir a la brevedad con su labor. ${ }^{47} \mathrm{El}$ folleto, de 16 páginas y letras grandes, seguía prácticamente todas las directrices presidenciales, aunque esta vez el autor decidió omitir su nombre. ${ }^{48}$

Esta cercanía de Cárdenas con el ámbito editorial reforzaba el empeño de los trabajadores de los Talleres por llevar a cabo las labores encomendadas por la "revolución". En este proceso además mencionaban constantemente a manera de símbolo el pasado del presidente como tipógrafo, lo que en términos generales al mismo tiempo servía para generar entre ellos una autopercepción de prestigio, de responsabilidad y de compromiso que los diferenciaba dentro del entramado de los funcionarios estatales. ${ }^{49}$ No fue extraño que en las reuniones sindicales algunos miembros de los Talleres destacaran sus labores como eje del cardenismo; no sólo preparaban el material de propaganda al respecto, sino que su experiencia servía como ejemplo a otro tipo de iniciativas y aunque no se trataba de una empresa del tamaño de Ferrocarriles Nacionales, su presencia por medio de sus publicaciones los dotaba de una importancia particular. La reducción de costos y también la velocidad con que hacían sus entregas era motivo de orgullo y de compromiso con la lucha revolucionaria. "En tres días - explicaba Eduardo Rico - entregamos a la Secretaría de Educación la obra Selección de Trabajos del Lic. Ignacio Altamirano. Un día para hacer la composición, formar, leer y releer; otro día para imponer, imprimir y doblar,

47 Entre los principales destinatarios encontramos al delegado de la Comisión Local Agraria y al Banco de Crédito Agrícola de Mérida, ambas instituciones con 2500 ejemplares. El resto de los folletos se repartió entre las estructuras políticas estatales y partidistas, el congreso local, los militares, los presidentes municipales y los profesores. "Lista de ejemplares remitidos", 15 de abril de 1935, en AGN, LC, c. 1301, exp. 704.1/73, sin foliar.

48 Anónimo [Luciano Kubli], El ejido en Yucatán.

49 Sobre el uso del prestigio en los procesos de organización laboral, véase Bello Chávez, Redistribución y cultura participante. 
y el tercero para alzar, coser, forrar, contar y entregar quince mil ejemplares". ${ }^{50}$ Esta velocidad les permitió editar entre 1935 y 1938 más de 12000000 de ejemplares de libros y folletos para uso gubernamental, mientras que consideraban haber producido $90 \%$ de la propaganda revolucionaria, que incluía tanto la realizada por el Estado como la perteneciente a organizaciones sindicales, políticas y empresas privadas. ${ }^{51}$ En una comparación recurrentemente utilizada, un libro de texto para alfabetizar producido por los TGN costaba 11 centavos, mientras que uno similar comprado en el mercado podía llegar a los 2 pesos..$^{52}$

Por este sentido de responsabilidad, la concentración de la labor editorial era un objetivo tan relevante, y por ello se involucraron en su implementación más allá de las labores que les correspondían. "Tenemos conocimiento - explicaba el sindicato de los TGN al presidente- como comprobación a nuestro aserto anterior, que algunas secretarías, como la de Educación, que entregó en los primeros días del pasado mes de junio, un pedido de $\$ 40000.00$, valor de libros de texto, a la casa del español Turanzas del Valle". ${ }^{53}$ La Secretaría de Comunicaciones había hecho algo similar con diferentes imprentas también dirigidas por extranjeros. Pero además acusaba a varios ministerios de fortalecer sus pequeños talleres con maquinaria,

50 Rico, "Pruebas contra la argucia de nuestros enemigos", pp. 57-62.

51 "La entrega de los Talleres Gráficos", El Nacional (7 mar. 1939), p. 3. Las cifras provienen de los propios Talleres. En las memorias del DAPP se detalla su producción editorial anual y los datos coinciden con estos impresionantes números, aunque no toda la producción puede considerarse como material propagandístico. Véase por ejemplo ArRoYo CH., Memoria del Departamento Autónomo de Prensa y Publicidad.

52 "Doce millones de libros baratos han producido", El Popular (9 mar. 1939), pp. 5 y 8.

53 "Carta del Sindicato de Trabajadores de los Talleres Gráficos de la Nación al presidente Lázaro Cárdenas”, 5 de julio de 1935, en AGN, LC, c. 372, exp. $432 / 8$, f. 35 . 
lo que aún a baja escala impactaba en la labor editorial. ${ }^{54}$ Para los trabajadores de los Talleres, la fluctuación en los encargos significaba directamente la amenaza de disminución de la planta laboral, lo que sumado a los elementos de carácter simbólico, impulsaba que una parte relevante de sus preocupaciones fuera velar porque se avanzara en el cumplimiento de dicha centralización. Antes de la administración de Cárdenas la nómina de funcionarios llegaba a 350, mientras que a mediados de 1935 ya había crecido a 500; en 1937 pasaron a 610 y en 1939 la cifra se había elevado a 777.55

Aunque según las normativas oficiales la concentración se había producido a mediados de la década de 1920, todavía durante el cardenismo podemos encontrar algunos casos de importantes imprentas ministeriales que no se habían fusionado con los TGN. Por mencionar uno de los ejemplos más destacados, sólo a principios de 1937 la Imprenta de la Secretaría de Relaciones Exteriores cumplió con el acuerdo presidencial. En palabras de los encargados de los TGN, uno de los problemas era que se "[...] trataba de una imprenta magníficamente organiza$\mathrm{da}$, con personal altamente calificado, con maquinaria moderna en perfectas condiciones de uso y espléndidamente cuidada, sin problemas de personal ni técnicos de ninguna especie". ${ }^{56} \mathrm{En}$ estas condiciones se puede entender por que su incorporación a los Talleres fue un proceso al que hubo resistencia. Para lograr este objetivo, uno de los primeros ofrecimientos se concentró directamente en los trabajadores, prometiéndoles el pago de

${ }^{54}$ La Dirección General de Educación Militar y la Comisión Nacional de Irrigación habían comprado un sistema tipográfico denominado Set-o-Type, que se consideraba uno de los mejores del momento. Véase Rico, "Los Talleres Gráficos de la Nación”, pp. 29-37.

55 “La entrega de los Talleres Gráficos”, El Nacional (7 mar. 1939), p. 3.

56 "Talleres Gráficos de la Nación. Informa sobre la situación prevaleciente en la antigua Imprenta de la Secretaría de Relaciones", 30 de enero de 1937, en AGN, DGI, primera serie, c. 82 , exp. 34, f. 1 . 
sus salarios ajustados al tabulador y además con el compromiso sindical de reconocer los derechos de antigüedad y escalafón. La ausencia de un presupuesto fijo para los TGN generaba dudas en los funcionarios de la imprenta de la SRE, aunque su delegado, Enrique Ibarra y Allende, avalaba el proceso. ${ }^{57}$ Este tipógrafo había sido el maestro de Lázaro Cárdenas en la Imprenta la Económica en Jiquilpan en 1909. En ese entonces Ibarra perdió una mano y tuvo que dejar por algún tiempo su trabajo como impresor, aunque había mantenido su relación con Cárdenas y en este momento crucial apoyaba las intenciones del presidente. De todas maneras, la precariedad financiera era tan notoria que no había dinero suficiente para cubrir los gastos relacionados con el transporte y reinstalación de las maquinarias. Finalmente, pese al temor de que se produjeran problemas "aislados” en el acomodamiento del nuevo personal, el director, Gustavo Ortiz Hernán, declaraba: "[...] nos felicitamos de que pasen a formar parte de nuestras filas, elementos tan bien capacitados, tan honestos y animados de tan buenos propósitos". ${ }^{58}$ No he encontrado declaraciones de los trabajadores de la SRE sobre este cambio.

Sin embargo, los que sí levantaron la voz fueron los funcionarios de la imprenta del Museo Nacional de Historia. De hecho, impulsaron la creación del Sindicato de Trabajadores de Artes Gráficas del Estado para organizarse en contra de la medida de centralización. Sus argumentos radicaban en que los trabajos especializados que realizaban eran una labor que los TGN no serían capaces de cumplir, aunque los intereses de los trabajadores fueran los mismos y su apego al cardenismo lo consideraran incuestionable. Después de reuniones, visitas oficiales y negociaciones, propusieron que la imprenta continuara en

\footnotetext{
57 Véase CáRdenas, Cárdenas por Cárdenas.

58 “Talleres Gráficos de la Nación. Informa sobre la situación prevaleciente en la antigua Imprenta de la Secretaría de Relaciones”, 30 de enero de 1937, en AGN, DGI, primera serie, c. 82, exp. 34, f. 2.
} 
el Museo, pero "[...] con más elementos para crear la Sección de Especialización de los Talleres Gráficos de la Nación" ${ }^{59} \mathrm{La}$ encuadernación de libros antiguos, la reproducción de códices, la investigación, entre otras actividades, no podían hacerse fuera del propio Museo. A cambio, los trabajadores no especializados pasarían a la planta de los TGN, reconociéndoles la antigüedad, sus categorías y el tabulador de salarios, "[...] así como usos, costumbres, derechos, obligaciones, participación en el Sindicato y Consejo Técnico Proletario". 60

La evaluación del director de los Talleres, Ortiz Hernán, sobre dicha imprenta no era muy halagüeña. A su juicio, en términos de infraestructura había importantes déficits, mientras que en lo relacionado con sus trabajadores destacaba: "Lentitud general en la mano de obra, pérdida frecuente de tiempo, indisciplina y ninguna costumbre de producir de manera organizada". ${ }^{61}$ Frente a ello, junto con el representante de los trabajadores del Museo, Ángel Garrido, presentó a Agustín Arroyo Ch., jefe del Departamento Autónomo de Publicidad y Propaganda (DAPP), ${ }^{62}$ dos proyectos alternativos. La primera propuesta coincidía con los planes presentados por los trabajadores de la imprenta y se basaba en la idea de que existían libros cuya producción era necesaria independientemente del costo que ello involucrara. Por esto, se justificaba la creación de una sección especialista del libro fino de los TGN. La segunda

59 "Carta de los trabajadores de la Imprenta del Museo Nacional de Historia a Anastasio Muñoz, Secretario General del Sindicato de Artes Gráficas del Estado", 23 de enero de 1937, en AGN, DGI, primera serie, c. 82, exp. 27, f. 3. 60 "Carta de los trabajadores de la Imprenta del Museo Nacional de Historia a Anastasio Muñoz, Secretario General del Sindicato de Artes Gráficas del Estado", 23 de enero de 1937, en AGN, DGI, primera serie, c. 82, exp. 27, f. 4. 61 "Memorándum. Imprenta del Museo Nacional", 30 de enero de 1937, en AGN, DGI, primera serie, c. 82 , exp. 27, f. 5.

${ }^{62}$ Unos meses después de su creación, la palabra propaganda fue reemplazada por prensa, con el fin de evitar el peso negativo que comenzaba a adquirir dicho concepto. 
propuesta consistía simplemente en cerrar la imprenta, conservar los aparatos de fotograbado y un pequeño departamento de encuadernación, deshacerse de las maquinarias obsoletas y reajustar a los trabajadores a la planta de los TGN. Este "reajuste” era explicado inmediatamente:

En realidad debe advertirse que prácticamente todo el personal del Museo resulta absolutamente innecesario en los TGN ya que no aporta nueva maquinaria que pueda explotarse y que, elementos como los fotograbadores, cajistas, prensistas de pie y encuadernadores, solo lograrían agravar un problema de surplus [sic] de personal que ya existe en esta casa. ${ }^{63}$

En la argumentación de Ortiz Hernán destaca la estrecha relación que establece entre hombre y máquina. Esta concepción se instaló fuertemente durante el periodo y afectó al conjunto de los trabajadores de las artes gráficas, especialmente mediante la implementación de importantes cambios tecnológicos. Su impacto en la concepción simbólica del trabajo fue muy relevante, pero aún más importante resulta que cada novedad implicaba la precarización y mecanización de una labor que se había basado en las habilidades manuales. ${ }^{64}$ Las nuevas máquinas no requerían largos aprendizajes ni obreros especializados, lo que a su vez impactó en las prácticas cotidianas de sus trabajadores y en la concentración de la labor editorial en grandes talleres y la quiebra de los pequeños. En un estudio de agosto de 1935 se señalaba que casi un cuarto de los trabajadores de este rubro se encontraba desempleado. ${ }^{65}$ Por este mismo motivo,

63 “Memorándum. Imprenta del Museo Nacional”, 30 de enero de 1937, en AGN, DGI, primera serie, c. 82 , exp. 27, f. 7.

64 BIL, "Proceso de trabajo", pp. 65-88.

65 SAlgado, El costo de la vida de los obreros de artes gráficas. Desde otra perspectiva se puede ver la crisis que atravesaba el sector en el incremento de la cantidad de quiebras, huelgas u otros conflictos. Véase, por ejemplo, "Carta 
puede entenderse que contra las palabras de Ortiz Hernán, el Consejo Técnico Proletario de los TGN se oponía a esta idea que "[...] sostiene que el trabajador debe ser un ente mecanizado, una especie de robot, casi una parte integrante de la máquina que maneja". ${ }^{66}$ Las contradicciones de un proyecto que apostaba por la innovación tecnológica como sinónimo de modernización y otro que veía en las máquinas el reemplazo de la fuerza laboral se instalaban entre los propios integrantes de los Talleres.

En ese contexto, Ortiz Hernán dejaba la decisión sobre el futuro de los operarios de la Imprenta del Museo en manos del jefe del DAPP, aunque la situación continuó escalando y algunos académicos decidieron intervenir antes de que se tomara una medida irreversible. El reconocido Andrés Molina Enríquez, adscrito al Departamento de Etnografía Aborigen, realizó gestiones ante Vicente Lombardo Toledano para evitar la salida de Jesús Tovar y Portillo (director de la imprenta, restaurador especializado e impresor), Eduardo Sánchez del Villar y Camilo Cámara. Según Molina Enríquez, éstos habían servido a la edición de libros y a la defensa de los trabajadores; además: “[...] el señor Cámara es un corrector de pruebas, como yo creo que no hay otro en la República, por su práctica y sus conocimientos de lenguaje" ${ }^{67} \mathrm{El}$ antiguo agrarista pedía a Lombardo que utilizara su liderazgo sobre los distintos sindicatos para resolver este conflicto intraestatal.

Más allá de la solución de éste y otros tantos problemas similares, ${ }^{68}$ es necesario destacar que la cada vez más importante

de la Alianza de Uniones y Sindicatos de Artes Gráficas del Distrito Federal a Lázaro Cárdenas”, 4 de abril de 1935, AGN, LC, exp. 523.2/1, 4 fs.

66 "Una visita al primer consejo técnico proletario de México", Frente a Frente, núm. 4 (jul. 1936), p. 23.

67 "Carta de Andrés Molina Enríquez a Vicente Lombardo Toledano", 3 de abril de 1937, en FHVLT, id. 17016, leg. 293, f. 1.

${ }^{68}$ Situaciones parecidas se presentaron en los talleres de las secretarías de Comunicaciones, Agricultura y en el Departamento de Salubridad. De hecho, la sindicalización de estas instancias había sido casi paralela. Ejemplo de ello 
función de los Talleres en el proceso de centralización estuvo asociada a su relación con el Departamento Autónomo de Publicidad y Propaganda creado a comienzos de 1937. Este espacio se transformó en el articulador de la estrategia propagandística a gran escala que desarrolló el cardenismo y en particular para los TGN esto significó la existencia de un organismo que mediaba entre ellos y las distintas dependencias gubernamentales. Aunque en un principio esto no estuvo claro ni dentro del gobierno ${ }^{69} \mathrm{ni}$ en los organismos externos.

Los sindicatos por ejemplo se vieron afectados por esta falta de certezas. Los que apoyaban al régimen, y especialmente aquellos dependientes del Estado, buscaron aprovechar la concentración editorial y apelaron directamente al "revolucionarismo" de las autoridades para imprimir sus periódicos, volantes o pasquines en los Talleres. Los trabajadores de este organismo manifestaron su disposición a apoyar a sus compañeros de lucha; pero recordando que no podían saltarse el proceso estatal de toma de decisiones, dejaron la última palabra a su director o al DAPP. ${ }^{70}$ Esto daba margen para que la decisión fuera discutida en las distintas esferas del gobierno y las respuestas dependieran de la coyuntura política. Así, los solicitantes eran enviados de una dependencia a otra sin que nadie asumiera la responsabilidad o, en el mejor de los casos, directamente se apelaba a no tener ese tipo de autoridad sobre los Talleres.

son el Sindicato de Obreros de Artes Gráficas de los Talleres de la Secretaría de Agricultura y Fomento, la Unión Revolucionaria de Obreros de los Talleres de la Secretaría de Comunicación y Obras Públicas, e incluso la Unión de Obreros de los Talleres Gráficos de la Penitenciaria del Distrito Federal.

69 Véase por ejemplo las dudas planteadas por Hacienda al nuevo Departamento en "Órdenes de impresión solicitadas por la Secretaría de Hacienda", 1937, en AGN, DGI, c. 7, exp. 24.

70 "Federación Nacional de Trabajadores del Estado solicita se imprima en los Talleres Gráficos de la Nación su periódico El Vanguardista” (abr. 1937), en AGN, IPS, c. 183, exp. 3. 
De hecho, desde mediados de 1937, cuando se pretendía evadir realizar trabajos de orden sindical o político, se apeló cada vez más a la autonomía de la institución y especialmente a la crítica situación financiera interna de los propios Talleres, pese a las normas que responsabilizaban al DAPP por el flujo de trabajo. ${ }^{71}$ Aunque muchas de las peticiones enfatizaban que los trabajadores se habían comprometido a cubrir parte del esfuerzo económico con su propia labor, las solicitudes eran rechazadas por la carga que significaban para la entidad. Incluso, a pesar de la importancia que el director de los Talleres, Ortiz Hernán, daba a la labor de la LEAR, en este periodo se vio obligado a recortar el subsidio que le otorgaba a la revista Frente a Frente..$^{72}$ Según John Lear el tema de fondo, si bien tenía mucha relación con los problemas financieros, se debió al avance del gobierno en la consolidación de su propia agenda, la cual exigía mayor control por parte de las autoridades encargadas, en este caso del DAPP. Por este motivo las iniciativas que provenían de agentes $\mathrm{u}$ organizaciones externas al propio gobierno comenzaron a ser consideradas cada vez con mayor distancia. El avance de la concentración de las labores editoriales del Estado permitía mayores niveles de planificación y restaba espacio para la creatividad de los actores externos.

\section{EL COOPERATIVISMO EN MARCHA}

Paralelamente al proceso de concentración, a nivel nacional aumentaba la conversión de distintas empresas o departamentos

${ }^{71}$ En la mayoría de las ocasiones las solicitudes pedían la gratuidad de los trabajos, e incluso en el caso de la Liga Nacional Campesina, no sólo pretendía el no pago por libros o tricromías, sino también de "todos nuestros trabajos de urgente publicidad". Véase "La Liga Nacional Campesina pide que hagan los Talleres Gráficos de la Nación les hagan las publicaciones sin costo alguno”, 27 de abril de 1937, en AGN, LC, c. 1390, exp. Q/242, f. 1.

72 Lear, Picturing the Proletariat, p. 295. 
en cooperativas y las asociaciones vinculadas a las artes gráficas se mostraban dudosas del carácter revolucionario que tenía este tipo de organizaciones. Los miembros de la Unión Linotipográfica de la República Mexicana se incomodaban cada vez que se informaba de la formación de una. Sus dirigentes, especialmente el antiguo miembro Carlos L. Gracidas, reconocían que las labores propias de estas entidades terminarían por alejar a los agremiados de sus deberes con la Unión. "A las sociedades cooperativas les encontramos multitud de peligros para la aspiración obrera: nos parecen incubadores de pequeños burgueses", ${ }^{73}$ explicaban. La CTM por su parte evidenció ciertas dudas, aunque siempre estuvo dispuesta a hacer concesiones en pos de la "unidad a toda costa". Éste fue precisamente el lema que definía la política del PCM hacia el cardenismo, por lo que podemos advertir de entrada que la posición del partido favorecía los planes de cooperativismo estatal, pero en la discusión interna era uno de los principales motivos de discrepancias entre la dirigencia representada por Hernán Laborde y los distintos delegados obreros. Así, la formación de cooperativas incomodaba, pero no fue cuestionada de manera sistemática sino hasta finales del sexenio. ${ }^{74}$

Uno de los tantos casos que alimentaba el debate fue la conversión de la Imprenta de la Universidad Nacional Autónoma de México. Esta imprenta estuvo ligada a extrabajadores de la Secretaría de Relaciones Exteriores afectados por la concentración en los TGN, que vieron su espacio laboral reducido. En 1935, a partir de la maquinaria de una editorial privada en quiebra,

73 "Carta de la Unión Linotipográfica de la República Mexicana a Vicente Lombardo Toledano”, 8 de junio de 1935, en FHVLT, id. 15173, leg. 263, f. 1. 74 La Unión Linotipográfica propuso entre otras alternativas la creación de cooperativas que tuvieran un consejo de administración en el que participaran representantes de los principales gremios y sindicatos a los que pertenecían los trabajadores, además de no incluir como miembros a ningún integrante de la gerencia. 
se creó la cooperativa que administró la Imprenta de manera autónoma, entregando $20 \%$ de las utilidades a la Universidad a cambio de poder realizar trabajos particulares. Entre sus fundadores encontramos a Pablo González Casanova, junto con otros académicos. Su vida como cooperativa durante el cardenismo estuvo atravesada por dificultades que sobre todo provenían, a juicio de Manuel T. Moreno, de "algunos funcionarios de segunda importancia de la Universidad”. ${ }^{75}$ Ya en 1938 había abandonado la figura de la cooperativa y vuelto a depender directamente de la institución educativa. Dadas las condiciones laborales, en un texto de aniversario donde se reproducen los nombres y los rostros de sus integrantes, podemos ver que algunos de los trabajadores de los Talleres pasaron a desempeñarse en esta Imprenta, por lo que las discusiones sobre el asunto debieron transitar de un lado a otro de manera fluida.

Los debates teóricos o político-ideológicos chocaban con las condiciones realmente existentes en el mundo del impreso tanto estatal como comercial. La crisis financiera no sólo afectaba a los TGN, sino que toda la red de entidades estatales vinculadas a las artes gráficas sufría el impacto del desorden interno, de las represalias empresariales locales y de los problemas económicos internacionales provocados por la posibilidad de una nueva guerra mundial. En otro eslabón de esta misma industria, la Productora e Importadora de Papel S.A. (PIPSA), también perteneciente al Estado, pero mediante la figura de sociedad anónima, se encontraba al borde de la quiebra y si subsistía se debía en buena medida a la venta de papel de envolver, algo que estaba muy lejos de sus postulados iniciales de ayudar a la producción de periódicos y libros a bajo precio.

Esta situación financiera fue la que motivó al gobierno cardenista y a los trabajadores de los Talleres a buscar alternativas de administración que permitieran la subsistencia de la

${ }^{75}$ Moreno, "Datos históricos de la Imprenta Universitaria". 
entidad. Una de las primeras de estas decisiones fue la obligación de contratar los trabajos directamente con el Sindicato y, según se redactaba en un acuerdo presidencial, además

[...] el Ejecutivo Federal tiene en cuenta que como aportación del mismo al sostenimiento de los Talleres Gráficos de la Nación, en condiciones de tal naturaleza que cada obrero reciba mejor remuneración por su trabajo que la que reciben los obreros de talleres particulares, debe admitir mayor presupuesto en las obras y trabajos que mande ejecutar. ${ }^{76}$

Con esto se subsanaba la competencia de los talleres comerciales, que muchas veces ofrecían realizar los trabajos a menor precio, pero a costa, argumentaba el Ejecutivo, de pagar salarios más bajos. Para que el resultado de la admisión de presupuestos más altos no perjudicara a las distintas dependencias gubernamentales, el Departamento Autónomo de Publicidad y Propaganda quedó encargado de vigilar y resolver cualquier distorsión o problema. Por lo tanto, asumió la condición de supervisar las acciones que tomaban el Sindicato y su Consejo Técnico Proletario, organismo que había sido creado en 1936, para coordinar las actividades en pos de la revolución social. ${ }^{77}$

El nuevo acuerdo presidencial tampoco fue capaz de solucionar los problemas económicos de los Talleres y rápidamente

\footnotetext{
76 "Acuerdo por el cual se previene que todo trabajo de imprenta que necesiten las dependencias del Ejecutivo Federal debe contratarse con el Sindicato que maneja los Talleres Gráficos de la Nación”, Diario Oficial (15 feb. 1937), p. 11.

77 En una comparación de cotizaciones para la edición de Anales históricos de la Confederación de Trabajadores de México, los TGN propusieron realizar el libro a un costo de 2.2 pesos por ejemplar, mientras los Talleres Gráficos Modelo cobraban 4 pesos. Los costos de la entidad pública eran de casi la mitad de los propuestos por la empresa privada. Aun así, pesaba la idea de que los TGN eran más onerosos. Véase "Cotización \#684”, 20 de abril de 1940, en FHVLT, id. 21485 , leg. 383.
} 
la posibilidad de crear una cooperativa se transformó en la propuesta que más convencía a los implicados. ${ }^{78}$ Ésta era una opción que había comenzado a discutirse incluso antes de que Cárdenas asumiera la presidencia. Una carta de 1935 volvía a reiterar esta posibilidad: "Nuestro sindicato, en diversas ocasiones ha recibido de Usted las promesas de que, cuando se capacitara técnicamente y supiera responder a su propia responsabilidad, se le entregarían los propios Talleres Gráficos de la Nación, para que colaborara en la Histórica Administración de Lázaro Cárdenas".$^{79}$ De hecho, el año anterior el director Quirós Martínez había escrito que los obreros estaban estudiando un vasto proyecto de reorganización, basado en sus "[...] aspiraciones de unificación cooperativista" ${ }^{80} \mathrm{Y}$ los mismos funcionarios habían solicitado directamente convertirse en una sociedad cooperativa de producción, de responsabilidad limitada, esperando que la maquinaria, el edificio y demás herramientas fueran vendidos por el Estado a dicho organismo. ${ }^{81}$ En esa ocasión se asociaba el establecimiento de la cooperativa con la instauración de un seguro obrero y los planes para construir una colonia destinada a los trabajadores.

Con estos antecedentes, el 13 de enero de 1938, mediante un acuerdo, Cárdenas convirtió a los Talleres en una Sociedad Cooperativa de Participación Estatal y Responsabilidad

\footnotetext{
${ }^{78}$ Este proceso de creación de cooperativas dedicadas al trabajo editorial siguió distintos caminos. En algunos casos se dieron a partir de la maquinaria que habían adquirido los organismos gremiales, en otros resultaron del esfuerzo por autonomizar la labor de determinados medios de comunicación: también hubo cooperativas forjadas por la quiebra de las empresas, y en otros casos fue debido a la intervención estatal. Véase, por ejemplo, "Carta del Sindicato de Artes Gráficas de Veracruz al presidente Lázaro Cárdenas”, 12 de julio de 1935, en AGN, $L C$, c. 372, exp. 432/8, f. 29.

79 "Carta del Sindicato de los Talleres Gráficos de la Nación al presidente Lázaro Cárdenas”, 25 de julio de 1935, en AGN, LC, c. 372, exp. 432/8, f. 25.

${ }^{80}$ Quirós Martínez, "El ideal de los trabajadores”, p. 25.

${ }^{81}$ Morales Torres, “Cooperativa, seguro obrero y colonia”, pp. 47-55.
} 
Suplementada, donde los trabajadores serían los socios de la entidad y contarían con el apoyo del Banco Nacional Obrero y de Fomento Industrial, pero no serían dueños de la maquinaria ni de las instalaciones. Casi un año después de esta decisión, el 9 de febrero de 1939, la Cooperativa finalmente llevó a cabo su constitución legal. En sus bases, publicadas por el Comité Ejecutivo del Sindicato de Trabajadores de los Talleres Gráficos, se incluía la realización de todo tipo de labores vinculadas a las denominadas artes gráficas, desde la corrección de estilo hasta la fabricación de bolsas de cartón. ${ }^{82}$ Esta clase de trabajos podía ejecutarse para "[...] las dependencias del Gobierno Federal, los gobiernos de los Estados, para las organizaciones de obreros de tendencia revolucionaria y para los particulares, cuando se trate de trabajos de índole cultural revolucionaria" ${ }^{83}$ En la asamblea que aprobó estas nuevas bases, también se decidió que cada socio aportaría 50 pesos para su implementación.

Mientras la creación de la cooperativa pareció tener un respaldo unánime, o al menos lo suficientemente mayoritario para acallar a sus críticos, lo que sí se discutió fue la figura adoptada. Algunos pensaban que la completa autonomía favorecía las capacidades de los obreros para librar las vicisitudes de un mercado en constante cambio, mientras otro sector apostaba por la participación estatal, como una forma de dotar de seguridad a los trabajadores y asignar responsabilidad a un Estado cuyos integrantes muchas veces se habían mostrado renuentes a confiar en los TGN. El Nacional, periódico oficial, buscaba aplacar la discusión señalando que: "Las disensiones evidenciaron que

${ }^{82} \mathrm{Al}$ igual que en el caso de PIPsA, este tipo de actividades podían resultar más rentables que la producción editorial. Los Talleres también se dedicaban a hacer sobres y hojas membretadas, envoltorios de cigarros o incluso cajas para cerillos. Véase "Demanda de los Talleres Gráficos de la Nación en contra de la Cerillera Nacional Los Ahuehuetes", 1935, en AGN, TSJDF, exp. 443633. ${ }_{83}$ Proyecto de bases de la Sociedad Cooperativa de Trabajadores de los Talleres Gráficos de la Nación, p. 11. 
entre una y otra forma del dominio de los trabajadores sobre la fuente de producción, no existe oposición de principios ni pugna fundamental de doctrina". ${ }^{84}$ En su sección editorial unos días antes había expuesto que la fórmula no desclasaba a los integrantes, ya que no se convertían en propietarios, sino en usuarios de los instrumentos estatales, y además las empresas constituidas de esta forma aceptaban el ingreso de nuevos trabajadores. "En las otras cooperativas, el capital se acumula y permite, al recibir más trabajadores, establecer la explotación de sus compañeros de clase" ${ }^{85}$ concluía el editorial. Bajo esta argumentación se explicaba que la votación en la asamblea de los trabajadores finalmente favoreciera la propuesta de cooperativa de participación estatal, aunque en dicha discusión intervinieron como oradores más de 20 trabajadores, algo muy poco común para estas instancias.

Para evadir las críticas del mundo sindical y gremial, el Sindicato optó por introducir en los nuevos estatutos una serie de mecanismos que impidieran la desvinculación de los cooperativistas de las luchas de los trabajadores. De ese modo, se incluyó entre las obligaciones de los socios: "Desarrollar en el orden material, en el intelectual y en el moral, labor de carácter revolucionario, tendiendo siempre a la vinculación de la Cooperativa con el movimiento obrero organizado y velando porque los postulados fundamentales que norman al cooperativismo de participación estatal, se mantengan incólumes en su contenido de clase" ${ }^{86}$ Otros apartados también pueden leerse no tanto asociados a un carácter prescriptivo, sino como un proyecto sobre lo que debería ser una cooperativa, lo que a

\footnotetext{
84 "Los Talleres Gráficos de la Nación, son entregados a sus trabajadores", El Nacional (9 mar. 1939), p. 5.

85 "Los Talleres Gráficos de la Nación en manos de sus trabajadores", El Nacional (6 mar. 1939), p. 5.

86 Proyecto de bases de la Sociedad Cooperativa de Trabajadores de los Talleres Gráficos de la Nación, p. 11.
} 
juicio de un redactor de El Nacional, convertía los estatutos en una nueva figura ejemplar del derecho obrero revolucionario. ${ }^{87}$ Entre estos elementos, se estableció la necesidad de crear un sistema de seguridad social que permitiera a los cooperativistas gozar de algunos beneficios que poco a poco iban adquiriendo los trabajadores del Estado. Un énfasis particular en este plano fue la inclusión de una lista de enfermedades profesionales que permitiría a los trabajadores acceder a un fondo médico. Para generar este listado los nuevos estatutos buscaban asegurar a los funcionarios dependiendo del departamento en el que trabajaran. Así, los fundidores y choferes eran protegidos en contra de la dermitis causada por agentes físicos; los escribientes en contra de los calambres profesionales; los laminadores de cobre y trituradores de metal contra la esclerosis del oído medio; y los tipógrafos, cajistas y prensistas contra uno de los problemas mayores del mundo editorial del periodo, la intoxicación por plomo. Este problema solían combatirlo con la ingesta de leche. Sin embargo, algunos relatos explican que, dadas las dificultades de obtenerla en las largas jornadas nocturnas, los tipógrafos y linotipistas optaban por otro tipo de "líquidos", un poco más espirituosos. ${ }^{88}$

En el plano de las prestaciones sociales es necesario recordar la evaluación que realizó posteriormente Arturo Anguiano. En general, a su juicio, este tipo de trabajadores, dadas las particularidades de las cooperativas, no recibían el séptimo día, ganaban un sueldo menor, no tenían vacaciones ni ninguno de los derechos que iban generando quienes eran parte del mercado laboral regular. En el caso de los Talleres Gráficos de la Nación, este tipo de beneficios no habían sido parte de las obligaciones

87 "Los Talleres Gráficos de la Nación, son entregados a sus trabajadores", El Nacional (6 mar. 1939), p. 5. Este modelo fue adoptado también por el departamento encargado de fabricar los uniformes del Estado y por algunos ingenios azucareros.

88 Bataille, Memorias de un extranjero. 
del Estado al no asignar un presupuesto a la dependencia. Sin embargo, en la medida en que estas retribuciones se comenzaron a generalizar, el Sindicato, por medio de su Consejo Técnico Proletario, había presionado directamente al presidente para obtener vacaciones (dos veces al año), ${ }^{89}$ el pago del sexto y séptimo día y servicio médico, el que estaba "[...] orientado en muy distinto sentido del que le dan las empresas capitalistas[...] El servicio médico de los TGN se dirige a curar al trabajador, no sólo de las llamadas enfermedades profesionales, sino de todas aquellas que hacen más pesada y dura su labor" ${ }^{90}$

Más allá de esta situación ejemplificadora, para sus críticos el problema político planeando por las cooperativas es que dichas entidades se formaron de arriba hacia abajo, por lo que, en lugar de ser parte de la lucha obrera, fueron el resultado de decisiones estatales que reforzaron el control del Estado. Este debate llenó las páginas de las publicaciones de izquierda del periodo también ha sido un tema recurrente en los años posteriores. ${ }^{91}$ Abarcar todas las líneas de argumentación en torno de esta temática está muy lejos de los objetivos de este artículo, pero a la distancia podríamos destacar que se consolidó la propuesta

89 "Sindicato de Trabajadores de Talleres Gráficos de la Nación solicita al presidente de la República”, 29 de noviembre de 1935, en AGN, LC, c. 1286, exp. 703.8/6.

90 "Un año de administración proletaria en Talleres Gráficos", Frente a Frente (mar. 1937), núm. 8, p. 28.

${ }^{91}$ La discusión mediática en torno al tema entre Rodrigo García Treviño, un economista marxista de la СTM, y algunos integrantes del PCM, fue una de las tantas que llenaron las páginas de los medios oficiales, de las revistas de izquierda y de las publicaciones comunistas. Un pequeño eslabón de este debate en Velasco, La administración obrera en las empresas. En 1940, cuando se expulsó a la dirección del PCM, uno de los argumentos utilizados por el grupo de Dionisio Encina para el descabezamiento del partido fue el apoyo que había dado a las cooperativas como forma de llegar al socialismo, lo que a su juicio era una desviación imperdonable. A esto se sumaban conflictos concretos con la Cooperativa de Artes Gráficas, que el propio PCM había formado para editar El Machete y los libros de Editorial Popular. 
de que finalmente sus dirigentes respondieron más al Estado que a los trabajadores, por lo que el paso a un régimen corporativista aparece como el resultado lógico del impulso a este tipo de organización productiva. ${ }^{92} \mathrm{Sin}$ embargo, como hemos visto a lo largo del texto, el proceso de creación de esta cooperativa de participación estatal no fue necesariamente en una sola dirección ni estuvo exento de sus propias contradicciones. Los intentos por transformarse en este tipo de organización fueron un proceso complejo que pasó por negociaciones en múltiples direcciones, tanto por diálogos con el Ejecutivo como por debates entre los trabajadores, pasando por discrepancias con el escenario sindical.

Si hay un elemento positivo que la mayoría de los autores destaca sobre este tipo de administración obrera es el proceso de politización que enfrentaron los miembros de las cooperativas. De hecho, en este caso fue tan marcada esta situación que las mujeres de los Talleres desempeñaron un papel fundamental en la organización y la participación política, lo que no era común en otros espacios vinculados con el mundo del impreso, caracterizado por una fuerte hegemonía masculina. Los artistas, al momento de pintar el mural mencionado al comienzo de este artículo, recurrieron al overol como símbolo de los trabajadores y, como vemos en algunas imágenes de archivo, este tipo de vestimenta era utilizado especialmente por las mujeres. ${ }^{93}$ Incluso, esta situación fue percibida socialmente, y por ejemplo, un subteniente del Ejército pidió a Lázaro Cárdenas que su hija, Agustina García Ramos de 16 años, y su sobrina Jovita

92 Para una perspectiva amplia de este problema véase Middlebrook, The Paradox of Revolution.

${ }^{93}$ Según el estudio de Salgado y un grupo de estudiantes de trabajo social, esta prenda de vestir estaba disponible en todas las casas de los obreros de las artes gráficas. Véase SALGADO, El costo de la vida de los obreros de artes gráficas, pp. 24 y ss. 
López Estrada de 18, pudieran trabajar en ellos. ${ }^{94}$ Dentro de la dependencia, las mujeres no sólo se desempeñaron en el departamento de presupuesto y contabilidad o como secretarias, labores que se habían abierto a recibirlas en otras instancias del Estado, sino que también trabajaron en las prensas, en el departamento de encuadernación, en el de cajas, en el de fotograbado, entre otros. ${ }^{95}$ Una de ellas expresó en 1934: "Convivir con los obreros de los Talleres Gráficos, sufriendo en las horas de ardua labor, y gozando de las satisfacciones que da el deber cumplido, ha sido hasta hoy el ideal de la mujer que trabaja en los Talleres". ${ }^{96}$ Por supuesto, este tipo de convivencia representaba desafíos de orden cotidiano, que a su vez daban cuenta de los conflictos típicos de una sociedad y un espacio laboral con la ya referida hegemonía masculina. Por ejemplo, en 1939, los sanitarios de las mujeres fueron utilizados como bodega de la sección de distribución del DAPP, por lo que siempre estaban entrando y saliendo hombres del lugar. El Sindicato de los Talleres defendió ante las autoridades del DAPP "[...] las justas protestas de las compañeras". ${ }^{97}$ Así, pese a la intromisión, la estructura organizativa hacía lo posible por cautelar los derechos de un sector de los trabajadores que se había mostrado muy involucrado en los procesos de sindicalización y politización. ${ }^{8}$ De hecho, en clave

94 "Vicente Ramos solicita ayuda para que su hija y sobrina, trabajen en los Talleres Gráficos de la Nación”, 4 de marzo de 1939, en AGN, LC, c. 1239, exp. 702.2/11183.

${ }^{95}$ Una lista completa de los trabajadores en 1933 muestra la presencia de mujeres en la mayoría de los departamentos. Véase "Carta de los trabajadores de los Talleres Gráficos de la Nación al presidente de la República”, 14 de septiembre de 1933, en AGN, $A R$, c. 16, exp. 139164-4.

96 De Parodi, “El ideal de la mujer en Talleres”, pp. 71-76.

97 "Memorándum del Consejo de Administración de los Talleres Gráficos de la Nación al jefe del Departamento de Distribución del DAPP”, 17 de agosto de 1939, en AGN, DGI, primera serie, c. 89, exp. 5, f. 46.

98 En el caso argentino en este periodo se produjeron contradicciones similares, que a juicio de Bil se debieron a la necesidad sindical de incorporarlas y 
negativa, algunos informes de los agentes confidenciales de Gobernación recalcaban que las manifestaciones callejeras en las que participaba este sindicato estaban compuestas por un importante número de mujeres. ${ }^{99}$

Finalmente, a diferencia de los procesos que afectaron a otras cooperativas, es relevante destacar que su formación no significó el fin de la sindicalización de los trabajadores de los Talleres, lo que tampoco fue un proceso terso y libre de conflictos. El Sindicato se mantuvo en funciones, aunque defendiendo sobre todo a los cooperativistas. Por este motivo, el 22 de septiembre de 1939 fueron cesados 24 funcionarios al constituir un sindicato alternativo para proteger los intereses de los trabajadores no pertenecientes a la cooperativa. Según el Estatuto Jurídico de los Trabajadores del Estado no podían formarse dos sindicatos en una sola dependencia gubernamental. Algunos de los impulsores llevaban más de cuatro años en los TGN, pero su antigüedad no había sido reconocida al momento de crear la cooperativa. ${ }^{100}$ Esto comenzaba a abrir un nuevo flanco de disputas y especialmente un cuestionamiento a la figura de esta entidad en la lucha de clases, aunque esto ya es parte de otro proceso.

\section{PALABRAS FINALES}

En 1935, una investigación colectiva de un grupo de estudiantes de trabajo social, liderada por Daniel Salgado, para referirse a los esquemas organizativos de los trabajadores de las artes gráficas llegaba a plantear que "[...] hasta hace poco había rasgos de corporación medioeval, especialmente entre los linotipistas,

defender su igualdad salarial, para que no fueran utilizadas para reducir costos y reemplazar a la mano de obra masculina. Véase BIL, "Proceso de trabajo". 99 “Elecciones para diputados federales”, 1937, en AGN, IPS, c. 183, exp. 3.

100 "Carta de Carlos Barranco, Salvador Méndez, Alejandro Marín, José Guadalupe R. Pérez y Felipe Fragoso al presidente Lázaro Cárdenas”, 25 de septiembre de 1939, en AGN, LC, c. 372, exp.432/8, f. 10. 
que sólo enseñaban su oficio a parientes suyos”. ${ }^{101} \mathrm{El}$ texto utilizaba cuidadosamente el pasado para referirse a esta condición. El periodo cardenista estuvo atravesado por cambios acelerados en este ámbito y si tomamos, por ejemplo, la variable “ingreso al espacio laboral” vemos cómo se pasó por intentos de control gremial con cláusulas de exclusividad, construcción de clientelas por medio de la incorporación a la burocracia, requerimientos político-sindicales, la exclusión cooperativista y a su vez el diseño de estatutos supuestamente incluyentes. $\mathrm{Y}$ aunque en diferentes momentos predominó alguno de estos esquemas, en ningún caso fueron excluyentes mutuamente; al contrario, tendieron a superponerse y establecer mecanismos que permitieran darles continuidad pese a los cambios formales. Lo mismo podemos verlo a nivel de procesos de aprendizaje, en la relación con los organismos sindicales o incluso en la implementación de tecnologías. En este último caso, fue evidente la coexistencia de espacios destinados al fotograbado, una técnica muy poco eficiente en comparación con el rotograbado, o incluso encuadernadores manuales compartiendo su quehacer con los operadores de las máquinas destinadas a ello. La conformación de un gran taller estatal permitió la convivencia de tecnologías que al menos en el plano de la "eficiencia” debían reemplazarse unas a otras. Esto nos permite reconsiderar la idea un tanto mecanicista de equiparar cambio tecnológico a modificaciones en el ámbito organizativo. Sin negar la evidente relación entre el proceso productivo y las características organizativas de los trabajadores, en el caso de los Talleres resulta claro que esta relación fue resultado de diversas negociaciones.

Lo interesante es que este tipo de componendas, como hemos visto a lo largo del texto, se desplegaron en tres niveles diferenciados. Por un lado, estuvo lo intraestatal, donde el cardenismo trató de impulsar su propia agenda y los trabajadores respondieron

101 SAlgado, El costo de la vida de los obreros de artes gráficas, p. 3. 
reapropiándose de dicho discurso para sus propios fines. Por otra parte, encontramos lo intergremial, donde las agrupaciones, partidos y sindicatos buscaban influir en las decisiones que los trabajadores tomaran respecto a las propuestas de mediano plazo realizadas por las autoridades gubernamentales. $Y$ finalmente pudimos ver un último nivel, correspondiente a la dinámica interna de los trabajadores, su quehacer cotidiano, sus rutinas, que de alguna manera impactaron en las dinámicas generales que intentaba desplegar el Estado cardenista. En todo caso, el devenir de esta particular dependencia no se asemeja a otros espacios estatales, como tampoco tiene un símil en el mundo editorial privado. Sin embargo, es relevante reiterar que la interacción de los tres niveles mencionados nos da luces para comprender cómo se articuló el Estado en determinadas coyunturas y tal vez también nos permitiría tener claridad sobre otros fragmentos o secciones poco relacionadas con el quehacer editorial.

En el presente caso, las posibilidades de intervención de los trabajadores en la escena pública y política mexicana no sólo estuvieron influidas por la apertura cardenista, sino que fueron resultado de las disputas, negociaciones y propuestas realizadas por los propios funcionarios. En su carácter de actores se insertaron en el escenario e interactuaron tanto con sus propios colegas como con dirigentes sindicales integrantes de otras dependencias, autoridades del ejecutivo, periodistas, artistas y escritores. Estas posibilidades nos ofrecen un panorama menos gris que lo que acostumbramos ver en la burocracia estatal, y al mismo tiempo algunas pistas para dotar de "rostros" y color a otros funcionarios en otros espacios estatales.

En este ámbito podemos incorporar a la discusión conceptos simbólicos e identitarios, como disciplina, compromiso, lealtad, entre otros, que nutrieron la autopercepción de estos sujetos. Estos elementos les permitieron diferenciarse de otros grupos de trabajadores y, como se pudo percibir a lo largo del texto, fueron construidos y reelaborados durante las crisis que afectaron a 
los Talleres. Su adscripción permanente como parte de la clase trabajadora, incluso una vez convertidos en cooperativa, no fue el resultado mecánico de sus condiciones laborales, sino una búsqueda intencionada, frente a la tensión que significaba estar cada vez más adscritos a la burocracia estatal, de convertirse simplemente en funcionarios administrativos.

Finalmente, el momento en el que se detiene la investigación, el establecimiento de una cooperativa de participación estatal, si bien fue un objetivo de los trabajadores desde principios de la década de 1930, no fue un resultado obligado. Esto no puede leerse como un proceso teleológico, que llevaba a los Talleres directamente hacia el cooperativismo. Al contrario, espero haber demostrado que fue parte de un proceso complejo, con devaneos y ambigüedades. Del mismo modo, este impulso cooperativista tampoco puede leerse como el desencadenador inexorable del régimen corporativista mexicano, con un sindicalismo dócil y antidemocrático como el actualmente existente.

\section{SIGLAS Y REFERENCIAS}

AGN, IPS Archivo General de la Nación, fondo Dirección General de Investigaciones Políticas y Sociales, Ciudad de México, México.

AGN, LC Archivo General de la Nación, fondo Presidente Lázaro Cárdenas, Ciudad de México, México.

AGN, DGI Archivo General de la Nación, fondo Dirección General de Informaciones, Ciudad de México, México.

AGN, $A R \quad$ Archivo General de la Nación, fondo Presidente Abelardo Rodríguez, Ciudad de México, México.

AGN, TSJDF Archivo General de la Nación, fondo Tribunal Superior de Justicia del Distrito Federal, Ciudad de México, México.

AGN, SHCP Archivo General de la Nación, fondo Secretaría de Hacienda y Crédito Público, Ciudad de México, México.

CEMOS Centro de Estudios del Movimiento Obrero y Socialista, Ciudad de México, México.

PCM Partido Comunista de México.

FHVLT Fondo Histórico Vicente Lombardo Toledano, Universidad Obrera, Ciudad de México, México. 
Anguiano, Arturo, El Estado y la política obrera del cardenismo, México, Ediciones Era, 1991.

Anónimo [Luciano Kubli], El ejido en Yucatán, México, Talleres Gráficos de la Nación, 1935.

Arroyo Ch., Agustín, Memoria del Departamento Autónomo de Prensa y Publicidad, México, DAPP, 1938.

Ashby, Joe C., Organized Labor and the Mexican Revolution under Lázaro Cárdenas, Chapel Hill, The University of Noth Carolina Press, 1967.

Bataille, León, Memorias de un extranjero que pronto dejó de serlo (México: 1931-1946), México, El Día en libros, 1987.

Bello Chávez, Guillermo, Redistribución y cultura participante. El caso de los trabajadores de cuello blanco en Montevideo (1943-1952), México, Centro de Investigaciones sobre América Latina y el Caribe, Universidad Nacional Autónoma de México, 2017.

BIL, Damián Andrés, "Proceso de trabajo y luchas obreras en los años '30: los trabajadores gráficos", en Izquierdas, 30 (2016), pp. 65-88.

Bohoslavsky, Ernesto y Germán Soprano, "Una evaluación y propuestas para el estudio del Estado en Argentina”, en Ernesto BoHosLavsKy y Germán SOPRANo (coords.), Un Estado con rostro bumano: funcionarios e instituciones estatales en Argentina (desde 1880 a la actualidad) Buenos Aires, Prometeo, 2010.

Cárdenas, Cuauhtémoc, Cárdenas por Cárdenas, México, Grijalbo, 2016.

Ceruso, Diego, "Los trabajadores gráficos entre 1916 y 1943: estructura sindical, influencia de la izquierda y organización en el lugar de trabajo", en Avances del Cesor, XIII: 14 (2016), pp. 43-61.

Córdova, Arnaldo, La politica de masas del cardenismo, México, Ediciones Era, 1974.

Cosío Villegas, Daniel, El estilo personal de gobernar, México, Joaquín Mortiz, 1974.

De Parodi, Enriqueta, "El ideal de la mujer en Talleres”, en Talleres GráFICOS DE LA NACIÓN, 1934, pp. 71-76. 
Editorial México Nuevo, “Explicación”, en Luis Rodríguez, Veinte discursos, México, Editorial México Nuevo, 1936.

Estatutos de la Unión de Obreros de Artes Gráficas de los Talleres Oficiales, México, s. e., 1921.

García, Higinio C., Justicia divina. Drama social en cuatro actos, México, s. p. i., 1924.

Herrera González, Patricio, "Vicente Lombardo Toledano y el Congreso Obrero Latinoamericano (1935-1938)”, en Relaciones, 138 (2014), pp. 109-150.

Hinojosa, Roberto, El tren olivo en marcha, México, Talleres Gráficos de la Nación, 1936.

Illades, Carlos, Las otras ideas. El primer socialismo en México 1850-1935, México, Ediciones Era, Universidad Autónoma Metropolitana-Cuajimalpa, 2008.

Kubli, Luciano, Sureste proletario. Apuntes de una jira fecunda, México, Talleres Gráficos de la Nación, 1935.

LeAL, Juan Felipe, Agrupaciones y burocracias sindicales en México: 1906/1938, México, Juan Pablos Editor, 2012.

Lear, John, Picturing the Proletariat. Artists and Labor in Revolutionary Mexico, 1908-1940, Austin, University of Texas Press, 2017.

León, Samuel e Ignacio Marván, La clase obrera en la historia de México. En el cardenismo (1934-1940), México, Universidad Nacional Autónoma de México y Siglo Veintiuno Editores, 1985.

López, Ricardo, ““Nosotros también somos parte del pueblo”: gaitanismo, empleados y la formación histórica de la clase media en Bogotá, 1936-1948”, en Revista de Estudios Sociales, 41 (dic. 2011), pp. 84-105.

López Orozco, Leticia, "Los murales de O’Higgins: una enseñanza histórica”, en Pablo O’Higgins. Voz de Lucha y de arte, pp. 91-111.

Middlebrook, Kevin J., The Paradox of Revolution. Labor, the State, and Authoritarianism in Mexico, Maryland, The Johns Hopkins University Press, 1995. 
Morales Torres, Lorenzo, "Cooperativa, seguro obrero y colonia”, en Talleres Gráficos de la Nación, 1934, pp. 47-55.

Moreno, Manuel T., "Datos históricos de la Imprenta Universitaria”, en Sindicato de Trabajadores de la Imprenta Universitaria, XV Aniversario1938-1953, México, Imprenta Universitaria, 1953, sin páginas.

Pablo O'Higgins. Voz de lucha y de arte, México, Fundación Cultural María y Pablo O’Higgins, 2004.

Ortiz, Gustavo, Chimeneas, México, México Nuevo, 1937.

Proyecto de bases de la Sociedad Cooperativa de Trabajadores de los Talleres Gráficos de la Nación, México, Talleres Gráficos de la Nación, 1939.

Quirós Martínez, Roberto, "El ideal de los trabajadores”, en Talleres Gráficos de LA NACIÓN, 1934.

Reza, Filiberto, "Pasado, presente y futuro", en Talleres Gráficos de la NACión, 1934, pp. 39-45.

Rico, Juan, “Los Talleres Gráficos de la Nación”, en Talleres Gráficos DE LA NACIÓN, 1934, pp. 29-37.

Rico, Juan, "Pruebas contra la argucia de nuestros enemigos", en Talleres Gráficos de la NACión, 1934, pp. 57-62.

Rodríguez, Luis, Veinte discursos, México, Editorial México Nuevo, 1936.

Salgado, Daniel, El costo de la vida de los obreros de artes gráficas en el Distrito Federal, México, Talleres Gráficos de la Nación, 1936.

Talleres Gráficos de la Nación, Homenaje de los obreros y empleados a los ciudadanos Álvaro Obregón, Plutarco Elías Calles, Abelardo L. Rodríguez y Lázaro Cárdenas, México, Talleres Gráficos de la Nación, 1934.

TAPia Ortega, Francisco, Grito y silencio de las imprentas. Los trabajadores de las artes gráficas durante el porfiriato, México, Universidad Autónoma Metropolitana-Xochimilco, 1990.

Velasco, Miguel A., La administración obrera en las empresas. Marxismo versus anarcosindicalismo, México, Editorial Popular, 1939. 